\title{
Etnomatemática, justiça social e sustentabilidade
}

UBIRATAN D'AMBROSIO ${ }^{\mathrm{I}}$

\section{Introdução}

$\mathrm{O}$ PROGRAMA ETNOMATEMÁtica é um programa de pesquisa que tem como foco entender como a espécie humana desenvolveu seus meios para sobreviver na sua realidade natural, sociocultural e imaginária, e para transcender, indo além da sobrevivência. Recorre à análise da história das ideias e à origem e evolução do comportamento e do conhecimento da espécie humana, em distintos ambientes naturais e socioculturais. A ideia central é a Etnomatemática, que surge do reconhecimento de que diferentes culturas têm maneiras diferentes de lidar com situações e problemas do cotidiano e de dar explicações sobre fatos e fenômenos naturais e sociais. Neste trabalho vou propor uma fundamentação para a análise de como essas diferentes maneiras se manifestam na matemática e também nas religiões, nas artes e nas práticas profissionais e do cotidiano, focalizando modos de observar, comparar, organizar, classificar, medir, quantificar e contar e inferir, que são as categorias básicas do fazer matemático. A proposta pode ser uma contribuição às reflexões sobre a epistemologia. Há um conflito, certa hostilidade, entre os enfoques tradicionais à epistemologia e aqueles que recorrem aos mais recentes desenvolvimentos da cognição e da neurofisiologia. Procuro superar esse conflito com um tratamento mais amplo da epistemologia a partir das reflexões sobre Etnomatemática, no sentido amplo que será apresentado neste trabalho. Como área de pesquisa em História e Filosofia da Matemática e suas implicações pedagógicas, a Etnomatemática surge na década de 1980 (D’Ambrosio 1985).

O surgimento de ideias matemáticas é reconhecido desde a pré-história (D’Ambrosio; Almeida, 2017). Diferentes maneiras do fazer matemático foram notadas na Antiguidade grega quando Heródoto descreve, na sua clássica História, outros povos e civilizações então conhecidas (Heródoto, 1988). Como são e como se originaram essas diferentes modos do fazer matemático é um tema de crescente interesse entre etnógrafos, antropólogos, linguistas, neurocientistas e, naturalmente, entre historiadores e educadores. No mundo contemporâneo, são muito importantes os livros pioneiros sobre Etnomatemática de autoria de Claudia Zaslavsky (1973) e do casal de matemáticos e antropólogos Marcia e Robert Ascher (1981).

Embora relativamente nova, a Etnomatemática é uma área florescente e muito ativa. O primeiro grupo internacional de pesquisa sobre Etnomatemática 
é o ISGEm International Study Group on Ethnomathematics, que foi fundado em 1985, numa reunião do NCTM/National Council of Teachers of Mathematics, em San Antonio, Texas. Logo foram criados grupos nacionais e regionais. Nesse curto período, foram realizados congressos internacionais e nacionais e existem várias revistas especializadas no Brasil e no exterior. O Primeiro Congresso Internacional de Etnomatemática, o ICEm-1 realizou-se em 1998, em Granada, Espanha. Os demais, a cada quatro anos, foram em Ouro Preto (MG), em Auckland, Nova Zelândia, em Towson, MD, nos Estados Unidos, em Maputo, Moçambique. O ICEm-6 realizou-se em julho de 2018 em Medellin, Colômbia. O ICEm-7 será em 2022, em Papua Nova Guiné.

\section{O Programa Etnomatemática}

O Programa Etnomatemática inicialmente focalizou história e filosofia da matemática, com implicações pedagógicas óbvias (D’Ambrosio, 1992). O foco do Programa Etnomatemática foi expandido para contemplar o sistema complexo de comportamento e conhecimento gerado e organizado por cada indivíduo (desde o nascimento até a morte) e por toda a espécie humana. Ambos, cada indivíduo e a espécie humana, desenvolvem estratégias para lidar com a realidade ampla em que está inserido. É importante esclarecer desde o início que considero realidade no sentido lato de fenômenos e fatos naturais, fisiológicos, sensoriais, emocionais e psíquicos, imaginários e as interações sociais. Simplesmente tudo, que está permanentemente mudando. A realidade é dinâmica. Logo o Programa Etnomatemática não é uma teoria final, e essa é a razão para considerar essa proposta um programa de pesquisa. É um programa necessariamente transcultural e transdisciplinar e utiliza métodos de pesquisa das ciências, da cognição, da mitologia, da antropologia, da história, da sociologia (política, economia, educação) e de estudos culturais em geral.

A proposta se concentra na geração e evolução de comportamento e conhecimento em dois focos aparentemente distintos:

- cada indivíduo da espécie humana e

- a espécie humana como um todo.

Ambos se inspiram mutuamente, como foi muito bem mostrado nos programas de pesquisa de Jean Piaget, Lev Vygostsky, entre outros. Eles mostram o quanto crianças e adultos podem nos sugerir o comportamento de toda a espécie humana. Deixam também claro que as emoções e tomadas de decisão resultam tanto de processos cognitivos quanto de processos emocionais e sociais. As relações com educação são óbvias.

O conceito de Etnomatemática é muito mais ambicioso do que o estudo das ideias e práticas matemáticas e das técnicas reconhecidas em diferentes grupos étnicos e em artesanato e profissionais e mesmo em civilizações diferentes, como é o foco principal da etnografia, da etnologia e da antropologia. Como será explicado adiante, eu uso o prefixo etno em um sentido muito mais amplo 
do que étnico e também matema e tica com significados mais amplos que na matemática como disciplina acadêmica.

A Matemática Acadêmica, que é universalmente praticada nos institutos de pesquisa e nos sistemas educacionais, é uma categoria ampla de conhecimento, uma construção abstrata originada nas culturas da bacia do Mediterrâneo e da Mesopotâmia (Iraque antigo) e das civilizações do vale do Nilo. Podemos dizer que a Matemática Acadêmica (e portanto a Matemática Escolar) tem como origem a Etnomatemática dessa ampla região ao redor do Mediterrâneo. Essa construção abstrata, muitas vezes chamada o estilo euclidiano, é baseada na lógica do tertium non datur. O estilo euclideano é o protótipo de rigor matemático. Mas esse estilo e os resultados obtidos a partir dele têm se mostrado insuficientes e inadequados como estratégia para lidar com a complexidade de fatos e fenômenos de todos os ambientes naturais e socioculturais. Muitos matemáticos acham que essas insuficiências não devem ser consideradas na matemática elementar, não devem ser consideradas nas escolas, desde o Fundamental ao Superior. Insistem que o estilo euclidano é a base de toda a evolução do pensamento, não só matemático e científico, mas de todas as áreas de conhecimento. $\mathrm{O}$ estilo euclideano é considerado padrão de rigor. Mas a dicotomia do "é ou não é", "certo ou errado", "bom ou mau" e tantas outras formulações do tertium non datur vêm sendo contestada, particularmente como estratégias de desenvolvimento cognitivo. O "pode ser", "talvez seja” vêm ganhando presença entre pensadores, particularmente entre matemáticos e cientistas. Os trabalhos de Max Planck, Albert Einstein, Luitzen E. J. Brouwer, Kurt Gödel e outros evidenciam isso, assim como a matemática fuzzy.

Como aprendemos do eminente matemático Wen-Tsun $\mathrm{Wu}$, a matemática na China antiga tinha um método de pensamento e estilo de apresentação muito diferente da matemática grega. Havia rigor seguindo um modelo distinto do estilo euclideano (Wu, 1987).

Reconhecemos construções abstratas ao estudar a história da matemática na Índia antiga, nas civilizações andinas, na África subsaariana, na Polinésia, de fato em todas as civilizações do mundo. Pode haver alguma semelhança nas construções abstratas em civilizações diferentes, mas elas são essencialmente distintas. Temos de compreender os intelectuais, os artesãos, os profissionais, as pessoas, a sociedade invisível nestas regiões, seus mitos e sistemas de valores, seus sistemas de conhecimento. Tudo está em permanente mudança. Temos também de considerar a dinâmica dos encontros de civilizações.

O Programa Etnomatemática é conceitualmente projetado como um programa de ampla investigação da evolução das ideias, das práticas e do conhecimento da espécie humana em diferentes ambientes culturais. Essencialmente, implica uma análise de como grupos de seres humanos geraram formas, estilos, artes e técnicas de fazer e de saber, de aprender e explicar, como lidam com situações e resolvem os problemas do seu cotidiano, do seu ambiente natural e 
sociocultural. Ao conceituar Etnomatemática, no sentido amplo, pratiquei um abuso etimológico com a apropriação "livre” de raízes gregas: techné [tica] significando maneiras, estilos, artes e técnicas; matema significando fazer e saber, as explicações, os entendimentos, o ensinar e apreender para lidar com situações e resolver problemas de seu próprio etno, que significa o meio ambiente natural, socioculturais e imaginário. Assim, usando essas raízes gregas, as maneiras, estilos, artes e técnicas [ticas] para fazer e saber, explicar, entender, ensinar e apreender [matema] no meio ambiente natural, sociocultural e imaginário [etno], podem ser sintetizados em uma palavra composta: ticas de matema em distintos etnos ou tica+matema+ etno ou, reorganizando a frase, etno+matema+tica ou simplesmente Etnomatemática. É fácil entender como essa construção etimológica conceitual deu origem à palavra Etnomatemática. Embora vários especialistas, particularmente antropólogos, etnógrafos e sociólogos, pesquisem disciplinas acadêmicas em diferentes etnos, como são a etno+botânica, a etno+musicologia, a etno+linguística, a etno+metodologia e várias outras etno+disciplinas, inclusive etno+matemática, eles baseiam suas pesquisas do ponto de vista de um observador, e recorrem a categorias do pesquisador, tentando encontrar semelhanças entre a cultura do pesquisador e a cultura do pesquisado. Sem dúvida, são pesquisas válidas. Mas é muito importante, para fundamentar essas pesquisas, identificar categorias próprias da cultura que se está estudando. Minha conceituação de etno+matema+tica reconhece estratégias cognitivas específicas de uma cultura para lidar com a realidade e categorias adequadas para construir conhecimento dessa cultura.

Um exemplo são os conceitos de tempo e de medição de tempo, que estão ligados ao desenvolvimento da aritmética. Expressam conhecimentos produzidos a partir de observações astronômicas e de uma visão específica de mundo. As culturas mediterrâneas desenvolveram uma forma específica de medir o tempo. Culturas da Amazônia, assim como culturas do Ártico e de outras regiões do planeta, terão outras observações astronômicas e, como consequência, outras visões de mundo. Produzem, socializam, atualizam e ensinam seus conhecimentos sobre tempo e sobre a medição do tempo. A pesquisa de João Severino Filho, junto ao povo Apyãwa, na Amazônia, mostra como essa cultura conceitua tempo e sua medição e como produz, atualiza e ensina esse conhecimento como parte intrínseca à sua prática cultural. A pesquisa só pode ser desenvolvida liberando-se das categorias acadêmicas e, tratando-se de culturas orais, recorrer a narrativas para entender suas maneiras de explicar e justificar essas práticas. Isso possibilitou ao autor contemplar, em toda sua complexidade, conceitos de rigor apoiados na personalidade e no jeito, do povo Apyãwa, de interagir com o outro e com seu meio natural (Severino Filho, 2015).

O Programa Etnomatemática vai muito além do conhecimento das culturas indígenas. Reflete também sobre impactos de novos desenvolvimentos científicos e tecnológicos no conhecimento matemático estabelecido no mundo acadêmi- 
co. O uso dos computadores para provar o teorema das Quatro Cores, há quase cinquenta anos, nos leva inevitavelmente a estender as fronteiras do saber e fazer matemático, questionando a lógica tradicional sobre as quais se baseia a matemática no estilo euclidiano. Essa temática também foi abordada por Wu-Wen Tsun. Observando que na China antiga havia mais preocupação com calcular, principalmente áreas e volumes, do que com demonstrar, como era o caso da Grécia antiga, Wu introduz o conceito e a metodologia de mecanização de provas, com ampla utilização de computadores. Seu foco é o desenvolvimento de algoritmos em vez de axiomatização e de abstrações para resolver sistemas de equações polinomiais multivariadas e aplicações à geometria elementar (Wu, 2000).

O Programa Etnomatemática focaliza as práticas matemáticas no cotidiano de profissionais, artesãos, do homem comum, da sociedade invisível. Por exemplo, Evanilton Rios Alves, em uma pesquisa exemplar com marceneiros, ouviu de um de seus entrevistados "A minha matemática é mais ou menos simples, uso medida linear, profundidade, altura, largura. Tiramos a medida de um quarto, uma sala, divide pra achar a medida dos móveis. É isso, matemática simples (sic)". A proposta do pesquisador foi como utilizar o que apreendeu dos marceneiros na formação inicial de professores no curso de Licenciatura (Alves, 2010). Um outro exemplo é a pesquisa de Tod L. Shockey sobre a prática de cirugiões cardíacos, cujas perguntas diretrizes são: i) que matemática esses cirurgiões utilizam para lidar com quantidade, espaço e probabilidades na prática cirúrgica; ii) qual o papel de procedimentos e conhecimentos conceituais e intuitivos nesse contexto (Shockey, 2000; 2002).

Seguem dois exemplos de orientandos que mostram, conceitual e metodologicamente, quão amplo é o Programa Etnomatemática. Ao conversar com meu aluno Ricardo Morelo sobre sua história de vida e seu interesse de pesquisa, prática que sempre adoto com meus orientandos, soube que ele é neto de imigrantes libaneses e lembra-se de que, quando criança, sua avó lhe ensinara como fazer operações no modo libanês. Assim surgiu o tema de sua pesquisa: descrever a maneira apreendida com a avó, relacionar com a maneira ensinada nas escolas brasileiras e procurar raízes históricas para ambos os métodos e como se influenciaram mutuamente (Morelo, 2016). Outro exemplo é do aluno Sergio Perine que em conversa me disse que sua religião era a umbanda. Interessei-me sobre o que é umbanda, uma religião brasileira surgida no início do século XX como uma mescla de kardecismo e de candomblé. Ficou clara a apropriação de símbolos, de natureza geométrica, própria dos cultos africanos. Assim surgiu a Geometria Sagrada presente nos cultos da umbanda. A partir daí a pesquisa de Sergio orientou-se para estudos de Geometria Sagrada, uma área muito ativa no mundo acadêmico (Perine, 2017).

Os exemplos apontados mostram como a recuperação de valores culturais revela conhecimentos matemáticos muito relevantes e podem ser um componente importante na redução da ansiedade matemática, um dos responsáveis 
pelo mau desempenho de alunos nas escolas.

Em todos esses exemplos, nota-se a capacidade de representar, em forma analógica, uma semelhança dos objetos e eventos da realidade externa e interna. A partir daí há condições para representações simbólicas e para os matema que se organizam como linguagem e a "matemática mais ou menos simples" a que se refere o artesão entrevistado por Alves. Está assim preparado o caminho para memória do fazer/saber, para imaginação e criatividade, para sentimentos, como belo e feio, e para fantasia. Tudo isso constitui a cultura do indivíduo.

A vertente historiográfica do Programa Etnomatemática é essencial, pois o programa trata da geração e da evolução do conhecimento na academia e nas práticas do cotidiano da sociedade invisível. A conceituação de pesquisa se aplica aos estudos históricos de culturas extintas e da dinâmica de encontro de culturas, no presente e no passado. Um exemplo na história da matemática é como, no século XIII, a introdução da nova tecnologia da aritmética com algarismos indo-arábicos por Leonardo Fibonacci mudou radicalmente não só a matemática dominante, mas também a Filosofia Natural e as demais ciências, e possibilitou a emergência da economia capitalista e as implicações em um novo modelo de organização social. Particularmente importante foi o desenvolvimento das grandes navegações e as consequentes conquistas e colonização. Em praticamente todos os períodos de história da humanidade algo semelhante se passa. Na pré-história isso é bem mostrado em (D’Ambrosio, 2017).

O Programa Etnomatemática recorre a fontes materiais, como monumentos e artefatos, escritos e documentos, mas também a fontes orais, preservadas nas memórias e nas práticas. Fatos, datas e nomes dependem de registros, mas também de outras conceituações de tempo e de lugar. O conceito amplo de fontes mostra que é necessário o diálogo com informantes, que são intelectuais, artesãos, profissionais, o povo, membros da chamada sociedade invisível.

A metodologia de pesquisa do Programa Etnomatemática consiste essencialmente nas etapas:

- Como práticas ad hoc e solução de problemas se desenvolvem em métodos?

- Como métodos se desenvolvem em teorias?

- Como as teorias se desenvolvem em invenção científica?

Não vou dar exemplos de como essa metodologia é praticada. Isso pode ser visto em inúmeras publicações, incluindo dissertações e teses. Recomendo a coletânea de trabalhos publicada na revista ETD-Educação Temática Digital (ETD, 2017) e no site Meus Recursos Etnomatemáticos, mantido por Daniel C. Orey.

A globalização provoca um questionamento sobre as culturas locais. Há um consenso internacional que culturas milenares lidaram com sabedoria com seu meio ambiente, embora seja muito difícil conciliar conhecimentos que foram organizados e estruturados em diferentes ambientes naturais e sociocultu- 
rais. Isso foi muito bem estudado pelo historiador inglês G. E. R. Lloyd, FRS. Embora seu principal interesse seja medicina, sua observação aplica-se a todas as áreas de conhecimento:

[...] a biomedicina [com dependência em uma bateria de testes] pronuncia-se sobre um caso individual e pretende afirmar o que os pacientes efetivamente sentem. Mas também as elites mais ou menos articuladas de estilos alternativos de medicina, focalizam a complexidade do que se acredita sentir-se verdadeiramente bem, e certamente seria temerário supor que a biomedicina nada tem a aprender com suas rivais [que são as medicinas tradicionais]. (Lloyd, 2009, p.101)

O mesmo se aplica à matemática, particularmente no seu ensino.

No encontro se reconhece o outro, o diferente, a essencialidade do outro e a dependência mútua de si mesmo e do outro e a natureza como a sustentação comum da vida. Isso leva a um comportamento primordial, o que implica a continuidade da vida, em seu sentido mais amplo. Esse comportamento primordial eu chamo a ética da diversidade:

- respeito pelo outro com todas as diferenças;

- solidariedade com o outro na satisfação de todas as suas necessidades;

- colaboração com o outro na preservação do suporte comum para a vida.

Essa ética precede qualquer noção de cultura e é mais ampla do que a subordinação a um sistema de valores. De fato, é transcultural.

\section{Educação, justiça social e sustentabilidade da civilização}

O que se passa nas escolas é preocupante. Os índices são cada vez mais baixos. Têm-se notícias de escolas depredadas por irresponsáveis, verdadeiros criminosos, do descaso de alguns governantes, igualmente criminosos, da burocracia oficial que impede inovação, de professores que desistem da profissão e buscam alternativas para uma vida com maior dignidade. Crianças fora das escolas são cooptadas e recrutadas para ingressar no crime organizado. Esse quadro terrível é constatado pelo noticiário da mídia e é evidente por uma leitura crítica de relatórios oficiais, nos quais se mostra friamente a situação, acompanhada de narrativas vazias e incoerentes e de promessas mentirosas. Lamentável, mas incontestável. O que fazer? Como educadores matemáticos, nos toca diretamente o fato que nossa disciplina tem sido instrumental na manutenção dessa situação. Matemática e alfabetização são as disciplinas que mostram pior rendimento nas escolas. Atribuo como causa os currículos obsoletos, desinteressantes e inúteis e a formação deficiente de professores. Tudo contribui para desencantar alunos e agravar esse quadro.

As consequências são o aumento da desigualdade social. As raízes da desigualdade social são muito complexas, intrínsecas ao modelo de civilização que a humanidade construiu desde os tempos primitivos, quando grupos se organizaram em cidades e surgiu uma estrutura de poder e de governança baseada na 
dicotomia entre "homem opressor" e "homem oprimido". A superação dessa situação é o surgimento, pela educação, de uma nova organização, de um "homem novo", como diz Paulo Freire (2013) na sua obra máxima, Pedagogia do oprimido, onde propõe igualdade, respeito, solidariedade e cooperação. Não basta dar aos oprimidos a oportunidade de acesso social para que eles ocupem a posição dos opressores. Um alerta sobre essa visão equivocada de Justiça Social nos é dado por Paulo Freire:

O "homem novo", em tal caso, para os oprimidos, não é o homem a nascer da superação da contradição, com a transformação da velha situação concreta opressora, que cede seu lugar a uma nova, de libertação. Para eles, o novo homem são eles mesmos, tornando-se opressores de outros. A sua visão do homem novo é uma visão individualista. A sua aderência ao opressor não lhes possibilita a consciência de si como pessoa, nem a consciência de classe oprimida.

Desta forma, por exemplo, querem a reforma agrária, não para se libertarem, mas para passarem a ter terra e, com esta, tornarem-se proprietários ou, mais precisamente, patrões de novos empregados.

Raros são os camponeses que, ao serem "promovidos" a capatazes, não se tornam mais duros opressores de seus antigos companheiros do que o patrão mesmo. Poder-se-á dizer - e com razão - que isto se deve ao fato de que a situação concreta, vigente, de opressão, não foi transformada. E que, nesta hipótese, o capataz, para assegurar seu posto, tem de encarnar, com mais dureza ainda, a dureza do patrão. Tal afirmação não nega a nossa - a de que, nestas circunstâncias, os oprimidos têm no opressor o seu testemunho de "homem". (Freire, 2013, p.18)

A busca desse "homem novo" está implícita no apelo, de 1955, de Bertrand Russell e Albert Einstein quando, em plena guerra fria, dizem:

Tentaremos não dizer qualquer palavra que apele para um grupo em detrimento de outro. Todos, igualmente, estão em perigo, e, se o perigo é compreendido, há esperança de que eles possam coletivamente evitá-lo. Temos que aprender a pensar de uma outra forma. Temos que aprender a perguntar a nós mesmos que passos podemos dar... [pois] [...] Como seres humanos apelamos aos seres humanos: lembrem-se de sua humanidade e esqueçam o resto. Se vocês podem fazer isso, o caminho está aberto para um novo Paraíso; se não forem capazes, perante vocês se apresenta o risco da morte universal. (Manifesto Pugwash, 1955)

Parafraseando Freire, Russell e Einstein, digo que é necessário um novo pensar sobre justiça social, básica para manter equilíbrio e segurança na sociedade. Devemos ir muito além da justiça social como correção de falta de oportunidades de acesso, inegavelmente necessário, mas buscar um novo pensar, um "homem novo", como diz Paulo Feire. Como matemáticos e educadores matemáticos sabemos que temos que desenvolver novos conceitos e técnicas nas nossas especialidades para lidar com a ameaça de extinção da civilização.

Ao longo da minha carreira, tenho me preocupado com o que está acon- 
tecendo nas escolas, nas práticas discriminatórias, na intolerância. Infelizmente, em alguns casos, esse comportamento é tolerado e até mesmo estimulado por professores, por administradores e até pelos pais, que se satisfazem em ter um lugar para deixar filhos enquanto tocam, das maneiras mais diversas, seu dia a dia. Muito tem sido dito e pesquisado sobre essa situação.

Em 1993, expressei minhas preocupações com a sobrevivência da civilização na Terra com dignidade para todos:

Embora a principal preocupação desta reunião seja a Educação Matemática, eu acredito estar autorizado a subordinar os meus comentários a um objetivo maior: a sobrevivência da civilização na Terra com dignidade para todos. E não se trata de meros jargões. O mundo está ameaçado, não só por agressões contra a natureza e o meio ambiente. Estamos igualmente preocupados com o aumento de violações à dignidade humana. Enfrentamos mais e mais casos da vida subordinada ao medo, ao ódio e à violação dos princípios básicos sobre os quais repousa a civilização. (D’Ambrosio, 1993)

Como educadores, nossa missão é preparar gerações para um futuro sem fanatismo, sem ódio, sem medo e com dignidade para todos. Mas pode não haver qualquer futuro. Nossa existência, como espécie, está ameaçada. Os nossos objetivos devem ir além de justiça social e dignidade para a espécie humana, devemos pensar na própria sobrevivência da espécie, que está ameaçada por um colapso social.

Como matemáticos e educadores matemáticos devemos nossa responsabilidade perante questões de sustentabilidade, de alterações climáticas e de pandemias, que são urgentes. $\mathrm{O}$ chamado à nossa responsabilidade foi bem colocado por Christiane Rousseau em 2011, como vice-presidente da Comissão Executiva da IMU/International Mathematical Union. Ela se refere ao crescente interesse na ciência da sustentabilidade e a atenção que o IMU deve dedicar a isso, como resposta a um apelo do ICSU/International Council of Scientific Unions. Ela diz:

Embora não seja novidade que os cientistas estejam envolvidos no estudo das alterações climáticas e questões de sustentabilidade, um novo sentimento de urgência se desenvolveu. Os sinais de alerta, cada vez mais numerosos, mostram que são necessárias medidas urgentes se quisermos salvar o planeta de um futuro desastroso, já que podemos não estar longe de um ponto sem volta: a mudança climática com eventos climáticos mais extremos, elevação do nível do mar com o derretimento das geleiras, escassez de alimentos e de água em um futuro próximo, devido ao aumento da população mundial e as alterações climáticas, perda de biodiversidade, novas epidemias ou espécies invasoras, etc. (Rousseau, 2011)

Esse apelo foi reiterado, em 2013, pelo cientista Martin Rees, FRS:

As principais ameaças à existência humana sustentável agora vêm de pessoas, não da natureza. Choques ecológicos que irreversivelmente degradam a biosfera poderiam ser desencadeados pelas exigências insustentáveis de uma crescente população mundial. As pandemias que se espalham rapidamente 
causariam estragos nas megacidades do mundo em desenvolvimento.

E as tensões políticas provavelmente resultam da escassez de recursos, agravada pelas alterações climáticas. Igualmente preocupantes são as ameaças imponderáveis das poderosas e novas tecnologias cibernéticas, biotecnologias e nanotecnologias. Na verdade, nós estamos entrando em uma era em que alguns indivíduos poderiam, através de erro ou do terror, provocar um colapso social. (Rees, 2013)

Qual a posição dos matemáticos com relação a isso? O matemático $\mathrm{Mi}$ khail L. Gromov, laureado com o Prêmio Abel em 2009, diz:

A terra ficará sem os recursos básicos e não podemos prever o que vai acontecer depois disso. Vamos ficar sem água, ar, solo, metais raros, para não mencionar petróleo. Tudo chegará, essencialmente, à escassez no prazo de cinquenta anos. O que vai acontecer depois disso? Estou assustado. Pode ficar tudo bem se nós encontrarmos as soluções, mas caso contrário, tudo pode chegar a um fim muito rapidamente. A matemática pode ajudar a resolver o problema, mas se não formos bem-sucedidos, não haverá mais matemática, estou com medo! (Gromov, 2010, p.403)

Juntando todos os alertas e relatórios e as sérias preocupações dos órgãos científicos responsáveis, não podemos ignorar uma possível situação de caos. Matemáticos e educadores matemáticos têm que evoluir nas suas práticas, tendo como objetivo uma civilização sustentável, com paz em todas as suas dimensões (paz individual, paz social, paz ambiental e paz militar) para construir uma sociedade com justiça e dignidade para todos. Mas o ensino da Matemática, em todos os níveis, inclusive a pesquisa matemática, tende a ignorar essas questões críticas que ameaçam a sobrevivência da civilização e ainda permanecem repetindo temas que deixam de ser prioritários em face da urgência da crise que ameaça a continuidade da civilização. Deve ser lembrado o que disse David Hilbert no Congresso Internacional de Matemáticos, em 1900, em Paris: “A história nos ensina a continuidade do desenvolvimento da ciência. Sabemos que cada época tem seus próprios problemas, que na era seguinte são resolvidos ou colocados de lado, como sem interesse, e substituídos por novos problemas" (Hilbert 2003, p.5).

Matemáticos e educadores matemáticos devem tomar essa observação de David Hilbert como um apelo para pensar de uma maneira nova. A mesmice não melhora o mau estado da Educação Matemática. Peço atenção especial para a ilusão perigosa de que melhores resultados na avaliação e testes são relevantes para a verdadeira qualidade da educação. É impossível negar que precisamos de um novo pensamento dentro da Educação Matemática.

Muitos dos que completam a educação média e superior, mesmo com péssimo aproveitamento em matemática, serão os futuros tomadores de decisão nas empresas privadas e em cargos públicos. Será impossível atingir esses tomadores de decisão e profissionais de outras áreas com um ensino obsoleto e desinteressante da matemática. Na verdade, insistir nesses programas é um esforço inútil quando pensamos em atingir setores importantes da sociedade. 
Esse é um desafio que deve ser enfrentado em estreita cooperação de matemáticos e de educadores matemáticos. Mais uma vez, cito Gromov na mesma entrevista: "É uma questão muito difícil, porque temos de projetar ideias matemáticas para as pessoas que trabalham muito longe da matemática - para as pessoas que tomam decisões na sociedade".

Vejo como o principal problema a inacessibilidade da narrativa matemática aos não iniciados, principalmente a população como um todo, pois seu linguajar é inacessível.

Durante alguns anos, tenho utilizado o conceito de "gaiola epistemológica" como uma metáfora para descrever sistemas de conhecimento. O conhecimento tradicional é como uma gaiola de pássaros. Os pássaros na gaiola comunicam-se numa linguagem somente conhecida por eles. São alimentados com o que está na gaiola, voam apenas no espaço da gaiola, veem e sentem apenas o que as grades da gaiola permitem. Eles se repetem, reproduzem e procriam. Mas não podem ver a cor exterior da gaiola. Uma situação semelhante pode acontecer com os estudiosos especializados. Os estudiosos na gaiola desenvolvem seu próprio jargão e aderem a padrões metodológicos e ontológicos rigorosos. Superar a mesmice acadêmica é um grande desafio. É frequente ver pesquisadores subordinando os seus alunos a temas propostos pelos orientadores, restringindo o seu espaço para a criatividade.

Não se trata de destruir as gaiolas epistemológicas. A organização em disciplinas conduz ao necessário avanço do conhecimento especializado. Mas, metaforicamente, as portas da gaiola devem estar abertas para sair e voltar com ideias novas apreendidas do mundo exterior. Essa é a proposta na obra de ficção Nova Atlântida, de Francis Bacon, publicada postumamente em 1627, na qual navegadores no Pacífico encontram uma ilha com uma sociedade perfeita. Nessa ilha imaginária, os cientistas e intelectuais estão na Casa de Salomão, mas periodicamente saem, viajam incógnitos pelo mundo, aprendem o que há de novo e voltam para sua casa. Lembro que o eminente filósofo Francis Bacon (1561-1626), autor de Novum Organum, é considerado um dos precursores da Modernidade.

A mesma ideia é proposta por Mikhail Gromov Na entrevista já citada:

Eu não apenas me concentraria em matemática, mas na ciência e na arte $\mathrm{e}$ em tudo o que pode promover a atividade criativa em jovens. Quando isso se desenvolve, podemos ter alguma influência, mas não antes disso. Estando dentro da nossa torre de marfim, o que podemos dizer? Estamos dentro desta torre de marfim e estamos muito confortáveis nela. Mas nós realmente não podemos dizer muito, porque não vemos bem o mundo. Temos que ir para fora, mas isso não é tão fácil. (Gromov 2010, p.401)

\section{Como sair da gaiola e estimular a criatividade ampla}

Criatividade é essencial. Precisamos de novas ideias, novas abordagens, para enfrentar os problemas que afetam o mundo. A nossa geração e as nossas 
abordagens não estão produzindo as mudanças globais para evitar o desastre total. Precisamos permitir que as novas gerações pensem de uma nova forma.

Para isso, precisamos de uma nova concepção de rigor, em que a integração de todas as ciências, particularmente matemática, com os conhecimentos tradicionais possa ser materializada de forma espontânea, sem traumas de natureza epistemológica. Isso exige coragem e audácia. Não podemos estar aprisionados a padrões rígidos de rigor. Imre Lakatos observou que os cientistas devem ser ativistas revolucionários, caracterizados como aqueles que acreditam que os quadros conceituais podem ser desenvolvidos e substituídos por outros melhores. Lakatos faz uma espécie de mea culpa filosófica, dizendo que "Nós somos os únicos que criam nossas prisões e podemos também, criticamente, demoli-las" (Lakatos 1978, p.20).

Devem-se considerar a importância, os métodos, o passado e o futuro da matemática e sua conexão entre matemática e áreas afins. M. Gromov sugere novas direções para o desenvolvimento da matemática, resultantes do contexto sociocultural e não apenas de necessidades conceituais e detalhes intrínsecos às teorias matemáticas estabelecidas. Precisamos de uma nova matemática.

Em um trabalho notável, M. Gromov faz considerações muito profundas sobre a natureza da matemática. Inspirado em reflexões históricas, ele diz:

Natureza e naturalidade das questões. Aqui estão algumas observações (breves, incompletas, pessoais e ambíguas) com a intenção de tornar mais claras, pelo menos terminologicamente, as questões levantadas durante as discussões que tivemos nesta reunião. "Natural" pode se referir a estrutura ou a natureza da matemática (admitindo que isto existe para poder argumentar), ou "natural" pode se referir à natureza humana. Nós dividimos o primeiro sentido em matemática (pura), lógica e filosofia, e o segundo, de acordo com estímulos (internos ou externos) de recompensa, em intelectual, emocional e social. Como podemos confiar que nossa mente, pressionada por ideias intelectuais, emocionais e sociais, vai chegar a verdadeiras questões de matemática, lógica e filosofia? (Gromov 2010, p.129)

E conclui o parágrafo dizendo: "quanto a mim, eu amo problemas não naturais, loucamente não naturais, mas muito raramente se encontram esses problemas!”.

As ideias de Gromov indicam claramente que os cientistas, engenheiros e, obviamente, matemáticos da nova geração vão precisar de atitudes mais amplas em relação à matemática.

Embora as considerações de Gromov destinem-se principalmente a pesquisadores matemáticos, é inegável que se constituem num grande desafio para os educadores matemáticos. É questionável se deveríamos insistir em consumir tempo de escola e energia ensinando conteúdo obsoleto. Deveríamos avançar mais rapidamente para os novos conceitos de matemática, recorrendo ao intelectual, emocional e social, a situações que estão fora da gaiola. 
O domínio de técnicas de efeitos visuais revolucionários, por exemplo, utilizando imagens e personagens irreais, gerados por computador, é o domínio de jovens equipados com software muito acessível, especialmente jogos, que lhes permitem criar cenários fantásticos, frutos de fantasia e criatividade.

A escola deve ser um espaço não só para instrução, mas principalmente para a socialização e para criticar o que é observado e sentido na vida cotidiana. Isso pode estimular a criatividade levando a uma nova forma de pensar.

A vida é caracterizada por estratégias para sobreviver (todos os comportamentos e ações básicas, visam "como" sobreviver), que é comum a todas as espécies, e para transcender (entender e explicar fatos e fenômenos, indo além da sobrevivência e perguntando "por quê"), que é um traço único das espécies homo. As estratégias de sobrevivência e de transcendência são geradas por cada indivíduo e, graças à sociabilidade e comunicação, são compartilhadas e socializadas com outros e constituem a cultura do grupo. Tudo isso é ignorado na abordagem tradicional, mecanicista, da Educação Matemática.

\section{Conclusão}

Nos anos 1970, propus o Programa Etnomatemática, que é um programa de pesquisa em História e Filosofia da Matemática, com implicações pedagógicas. A essência do programa é lidar com situações reais e problemas recorrentes ao conhecimento acumulado do indivíduo, como mencionado nos parágrafos anteriores. Para trazer isso para as escolas, há o duplo desafio de inovar conteúdos e métodos. Conteúdos e métodos são inseparáveis. Descartes deixou isso bem claro no Discurso do Método.

As implicações pedagógicas do Programa Etnomatemática para o ensino da Matemática escolar, em todos os níveis de escolaridade, recorrem a conteúdos abrangentes, provenientes de tradições e também a recentes avanços da matemática. Os conteúdos na Educação Matemática tradicional são um arranjo engessado de teorias e técnicas desenvolvidas, muitas vezes há centenas de anos, acumuladas em ambientes acadêmicos, em gaiolas epistemológicas e em torres de marfim. Mesmo assim, é possível, no ensino tradicional, organizar as aulas procurando atalhos e novas organizações e aplicações de técnicas e teorias, sobretudo com os amplos recursos oferecidos pelas novas tecnologias de informação e comunicação. Os professores podem contextualizar os conteúdos através de problemas formulados em termos da vida real, do cotidiano. Lamentavelmente, muitos criam problemas e questões artificiais, descontextualizadas, como mero mecanismo repetitivo para ilustrar teorias. $\mathrm{O}$ que podemos chamar de situações e problemas "realmente reais" estão lá, fora das gaiolas, não "inventadas" pelo professor. Deverão ser reconhecidas e tratadas com métodos ad hoc criados pelos indivíduos, alunos ou pesquisadores. Isso foi claramente mostrado por Descartes no Discurso do Método. As formas ad hoc para lidar com fatos e fenômenos, situações e problemas, podem evoluir para métodos individuais e compartilhados, socializados. Tudo isso é muito dinâmico, em diferentes níveis de compreensão. 
Esclareço que me refiro a situações e problemas "realmente reais" como aqueles que estão relacionados a fatos e fenômenos percebidos pelos indivíduos, de acordo com suas estruturas sensoriais e mentais. Eu entendo a realidade como artefatos, tudo que é material, que existe, existiu ou existirá, mais mentefatos, que são as abstrações, o imaginário, as ilusões e desilusões, sonhos e crenças, mesmo a ficção, que pertencem à mente de cada indivíduo. Os mentefatos são acessíveis e informam apenas o indivíduo que os gerou. De muita importância são os símbolos, responsáveis pela transição de artefatos a mentefatos. Os símbolos são artefatos, mas adquirem valor e significado como mentefatos. Sobretudo nas religiões, é da maior importância o simbólico associado a artefatos. Um exemplo é a cruz. Artefatos e mentefatos socializados são chamados sociofatos. As palavras artefatos, mentefatos e sociofatos foram introduzidas pelo biólogo Julian Huxley (1887-1975) como base para uma teoria da cultura (Huxley, 1955). Essas palavras são usadas também em semiótica cultural.

Os artefatos, naturais e artificiais, são acessíveis e informam, através dos sentidos e da comunicação, indivíduos que os interpretam e os assimilam como mentefatos. A partir daí, os indivíduos criam representações, modelos da realidade, originados dos artefatos a que tiveram acesso. Esse é o princípio básico da modelagem, especialmente a modelagem matemática, uma disciplina de crescente importância e afinidade com o Programa Etnomatemática (D'Ambrosio, 2018).

O maior objetivo da Educação, em um sentido amplo, é ajudar as pessoas a se comunicarem. Para isso é necessário que as pessoas produzam, a partir dos mentefatos por elas criados, artefatos que possam ser captados por outros. Esse é o passo para a comunicação. Aprender a gesticular, a falar, a desenhar, a contar, a escrever e outras produções, particularmente artísticas, permitem que o indivíduo materialize seus mentefatos, suas ideias, em artefatos, e somente assim poderão ser captados e interpretados por outros. Na verdade, esses são passos evolutivos iniciais de cada criança, bem como passos evolutivos das espécies homo. As práticas assim encaminhadas são típicas do Método de Projetos, uma das mais significativas tendências da Educação Matemática e a metodologia mais adequada em resposta à vertente pedagógica do Programa Etnomatemática.

\section{Referências}

ALVES, E. R. Etnomatemática. Multiculturalismo em sala de aula: a atividade profissional como prática educativa. São Paulo: Porto de Ideias, 2010.

ASCHER, M.; ASCHER, R. Mathematics of the Incas: Code of the Quipu. New York: Dover Publications, 1981.

D'AMbrosio, U. Ethnomathematics and its Place in the History and Pedagogy of Mathematics. For the Learning of Mathematics, v.5, n.1, p.41-8, 1985.

. Ethnomathematics: A Research Program on the History and Pedagogy of Mathematics with Pedagogical Implications. Notices of the American Mathematical Society, v.39, n.10, p.1183-5, December 1992. 
D'AMBROSIO, U. Diversity and Equity: An Ethical Behavior. In: PROCEEDINGS OF THE 15TH ANNUAL MEETING OF THE NA CHAPTER OF PME, Pacific Grove, CA 1993 (ERIC ED 372 917), p.31.

Mathematical Modelling in Education Research and Practice: Cultural, Social and Cognitive Influences. In: STILLMAN, G. A.; BLUM, W.; BIEMBENGUT, M. S. (Ed.) International Perspectives on the Teaching and Learning of Mathematical Modelling. S. 1.: Springer International Publishing AG, 2018.

D'AMBROSIO, U; ALMEIDA, M. C. Ethnomathematics and the Emergence of Mathematics. In: ADAM, J. W.; BARMBY, P.; MESOUDI, A. (Ed.) The Nature and Development of Mathematics: Cross Disciplinary Perspectives on Cognition, Learning and Culture. New York: Routledge, 2017. p.69-85.

ETD. Dossiê sobre Etnomatemática na revista eletrônica ETD - Educação Temática Digital, Campinas, v.19, n.3, 2017. Disponível em: < https://periodicos.sbu.unicamp. br/ojs/index.php/etd/issue/view/1404>.

FREIRE, P. Pedagogia do oprimido. 17.ed. São Paulo: Paz e Terra, 2013.

GROMOV, M. Interviewed by M. Raussen \& C Skau. Notices of the AMS, v.57, n.3, p.391-409, march 2010a.

Spaces and questions. In: ALON. N. et al. (Ed.) Visions in Mathematics: GAFA 2000 Special Volume, Part 1. New York: Birkhäuser, 2010. p.118-161.

HERÓDOTO: História. 2.ed. Trad. Mário da Gama Kury. Brasília: Editora UnB, 1988.

HILBERT, D. Problemas Matemáticos. Revista Brasileira de História da Matemática, v.3, n.5, p.5-12, 2003.

HUXLEY, J. S. Evolution, Cultural and Biological, Yearbook of Anthropology, 1955, p.2-25.

LAKATOS, I. The methodology of scientific research programmes. Philosophical Papers Volume 1. Ed. John Worrall and George Currie. Cambridge: Cambridge University Press, 1978. p.20.

LLOYD, G. E. R. Disciplines in the Making. Cross-cultural Perspectives on Elites, Learning and Innovation. Oxford: Oxford University Press, 2009. p.92.

MANIFESTO PUGWASH: Statement: The Russell-Einstein Manifesto, 1955. Disponível em: <https://pugwash.org/1955/07/09/statement-manifesto/>.

MEUS RECURSOS ETNOMATEMÁTICOS. Disponível em: <https://sites.google. $\mathrm{com} /$ site/meuetnomate/>.

MORELO, R. G. Etnomatemática - uma visão sobre o processo de multiplicação árabe - Gelosia, São Paulo, 2016. Dissertação (Mestrado) - Universidade Anhanguera. São Paulo, 2016.

PERINE, S. Os significados mítico-religiosos das figures geométricas como símbolos na religião de Umbanda Sagrada. São Paulo, 2017. Dissertação (Mestrado) - Universidade Anhanguera. São Paulo, 2017.

REES, M. Editorial. Science, v.339, 8 Mar. 2013.

ROUSSEAU, C. Editorial. Newsletter International Mathematical Union, IMU-Net 47: May 2011. 
SEVERINO FILHO, J. Marcadores de tempo Apyãwa. A Solidariedade entre os povos e o ambiente que habitam, Rio Claro, 2015. Tese (Doutorado) - Faculdade de Filosofia, Ciências e Letras. Universidade Estadual Paulista "Júlio de Mesquita Filho". Rio Claro, 2015.

SHOCKEY, T. L. Ethnomathematics of a Professional Class: Thoracic Cardiovascular Surgeons, Topic Study Group 21 [Ethnomathematics] in ICME 9, Tokyo, 2000.

. Etnomatematica de uma Classe Profissional: Cirurgioes Cardiovasculares, $B O-$ LEMA, v.15, n.17, p.1-19, 2002.

WU, W.-T. Recent studies of the history of Chinese mathematics. In: PROCEEDINGS OF THE INTERNATIONAL CONGRESS OF MATHEMATICIANS, v.1, 2, Berkeley, Calif., 1986, 1657-1667, Amer. Math. Soc., Providence, RI, 1987.

Mechanical geometry theorem-proving, mechanical geometry problem-solving and polynomial equations-solving. Mathematics and its Applications, 489. Kluwer Academic Publishers Group, Dordrecht; Science Press, Beijing, 2000.

ZASLAVSKY, C. Africa Counts: Number and Pattern in African Culture. Chicago: Lawrence Hill Books. 1973.

RESUMO - O Programa Etnomatemática será apresentado como um programa de pesquisa sobre conhecimento e comportamento humanos, tendo como foco principal História e Filosofia da Matemática em diversas culturas e suas implicações pedagógicas. São dados exemplos de pesquisa recente sobre Etnomatemática e será feita uma discussão sobre justiça social e o estado do mundo e sustentabilidade. Será mostrado como a Etnomatemática pode contribuir para fazer face às ameaças à sustentabilidade e colaborar para evitar o que pode ser um colapso da civilização.

PALAVRAS-CHAVE: Etnomatemática, Justiça social, Sustentabilidade, Gaiolas epistemológicas.

ABSTRACT - The Ethnomathematics Program will be presented as a research program on knowledge and human behavior, focused on the History and Philosophy of Mathematics in different cultures and their pedagogical implications. Examples of current research on Ethnomathematics will be given, and social justice and the state of the world and sustainability will also be discussed. It will be shown how Ethnomathematics can contribute to face the threats to sustainability and cooperate with efforts to avoid the collapse of civilization.

KEYWORDS: Ethnomathematics, Social justice, Sustainability, Epistemological cages.

Ubiratan D'Ambrosio é doutor em Matemática pela Universidade de São Paulo, professor emérito da Universidade Estadual de Campinas (Unicamp) e docente permanente do Programa de Pós-Graduação em Educação Matemática da Universidade Anhanguera de São Paulo (Unian) e professor credenciado dos Programas de Pós-Graduação em História da Ciência da Pontifícia Universidade Católica de São Paulo. @ - ubi@usp.br

Recebido em 23.7.2018 e aceito em 15.8.2018.

${ }^{\text {I } U n i v e r s i d a d e ~ E s t a d u a l ~ d e ~ C a m p i n a s, ~ C a m p i n a s, ~ S a ̃ o ~ P a u l o, ~ B r a s i l . ~}$ 